\title{
Fossil energy: From conventional oil and gas to the shale revolution
}

\author{
Mario Marchionna \\ Saipem S.p.A. - Via Martiri di Cefalonia 67, 20097 San Donato Milanese (MI), Italy
}

Summary. - The fossil fuels have provided more than $80 \%$ of the total energy consumption for more than 100 years; although in perspective renewables are expected to be the fastest growing energy sources, it is likely that fossil fuels will dominate energy use at least through 2050. This is still due to the increased worldwide need for energy, to their superior energy intensity and reliability and to the very huge numbers that underline world exposition to fossil fuels, not easily substitutable. A few brief considerations, regarding the chain of production, transport and use of the energy carriers, make us realize that the success that oil has had as an energy source cannot be attributed only to its great availability and the relatively cheap price but also to the ease with which liquid hydrocarbon derivatives can be transported, stored and distributed for their final use. In fact, their liquid state enables their energy density per unit of volume to be optimized, and this has great advantages especially for the storage and the distribution of the carrier. This does not mean that there are not challenges and dilemmas in the exploitation of conventional reserves, such as for example the decline of great reservoirs for lacking of suitable technology and reservoir management, the increased produced water from oil reservoirs and related management and the need to cope with the issue of climate change due to the $\mathrm{CO}_{2}$ emissions. Attention will then be paid towards unconventional resources, especially those that have lead to the "shale" revolution: the deployment of huge reserves of shale oil and gas have deeply modified the overall energy picture in the last ten years, especially in the United States. By moving towards 2040-2050, oil and gas will remain crucial energy components, maybe with some less crude-oil production but more natural gas and higher use of electricity, produced both by gas and by renewables and also pushed by the advent of electric vehicles. 


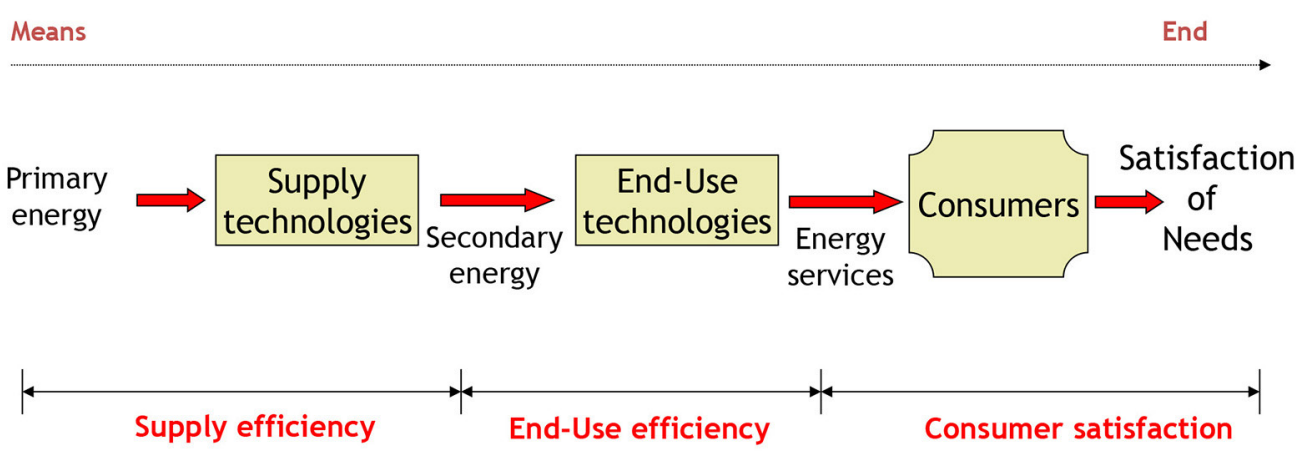

Fig. 1. - Conversion of primary energy to energy services.

\section{1. - Introduction - from sources to market: energy carriers}

Modern economic systems depend to an ever-increasing extent on the availability of energy, both for their operation and, in particular, for their development. The various forms of energy, however, are not the same, as they differ in their availability, profitability, usability and efficiency with respect to their end-use.

None of the different forms of energy available (fossil fuels such as oil, natural gas, coal, fissile materials, and renewable sources such as solar or wind power, hydropower, etc.) is capable by itself of satisfying the energy needs of the society that are linked to the main markets: the market supplying heat (or cold), mobility and transport, and ancillary services (mechanical, electronic, etc.). It is therefore necessary to introduce forms of energy that can guarantee a better link between the availability of energy sources and the particular use required: it is just the sector where energy carriers play their special role [1].

The energy carrier is a secondary form of energy which lends itself to being transported (often by means of special networks) to the place of use (fig. 1). It consists of either a transportable substance that can easily release the energy contained in it (as in the case of solid, liquid or gaseous fuels, steam, hot water, etc.), or of electricity (electric energy). The latter at present best enables its energy content, produced from the most varied primary sources, to be exploited for the needs of the end-user.

In only a few cases, it is not strictly necessary to introduce an energy carrier as the primary source is sufficiently versatile: for example, natural gas is capable of heating houses, fuelling motor vehicles, etc., but it is not always the most suitable form of energy for every use (it is not used as aircraft fuel or not yet in maritime transport, whereas it is used for road traction, but only at a very limited amount). However, there is always a natural gas treatment stage to remove not just carbon dioxide and nitrogen, but also hydrogen sulphide and the higher hydrocarbons, which are known as "natural gas liquids". It would thus be more correct to consider natural gas as an energy source, whereas methane, used commercially, should be regarded as an energy carrier. 


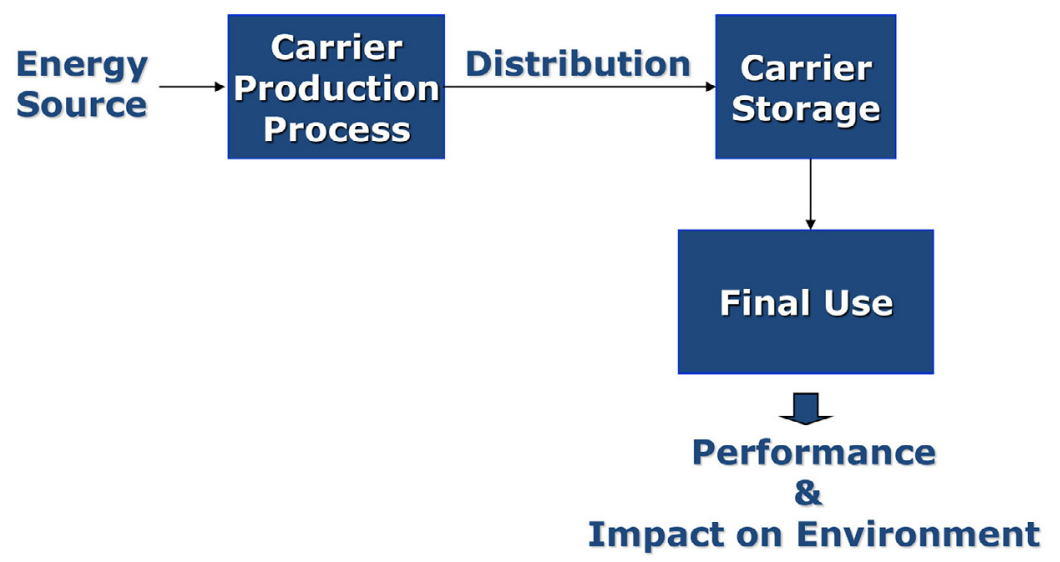

Fig. 2. - From sources to energy carriers till to the final use.

1`1. Life cycle of the energy carrier. - The various phases involved from generation to the end-use of an energy carrier constitute its "life cycle". The basic operations involved in the life cycle of an energy carrier are (fig. 2): a) generation using the primary fuel; b) transport (when required); c) storage (when required); d) distribution; e) enduse (with consequent impact on the environment, both in local terms in the form of emissions, and in global terms of efficiency in conserving the energy contained in the primary fuel throughout its transformation cycle).

The operations are not necessarily carried out in the aforementioned order; for example, storage could even precede transport or could be carried out at the same time as the final use (as in the case of motor traction). Linking energy sources with the market therefore entails technological and strategic choices as far as the processes for obtaining the carriers, the logistics of the sources and the end-uses are concerned.

On these grounds, there are a few considerations to be made:

- some carriers are dedicated to well-defined uses; for example, the use of gasoline and of diesel gas-oil is dominant in motor traction;

- among fossil fuels, crude oil has practically no direct use, but is converted in the refinery into the various liquid carriers that feed a relevant part of the end-uses;

- carriers are distinguished also by their different physical form: gaseous for methane and hydrogen; liquefied gas for LPG (Liquefied Petroleum Gas); liquid for all petroleum derivatives, and biofuels such as ethanol and biodiesel; solid for some other fuels; less easily definable in the case of electricity, for which the real carrier is an electric current, i.e. a flow of electrons.

These brief considerations, regarding the chain of production, transport and use of the energy carrier, make us realize that the success that oil has had as an energy source cannot be attributed only to its great availability and the relatively cheap price but also, 
and perhaps above all, to the ease with which liquid hydrocarbon derivatives can be transported, stored and distributed for their final use. In fact, their liquid state enables their energy density per unit of volume to be optimized, and this has great advantages for the storage and the distribution of the carrier. Actually, this aspect is also reflected in the higher price attributed to the "liquid" calories compared with "gaseous" and "solid" calories.

On the other side, the demand for electricity is going to and will go on increasing in the years to come, both in the industrialized countries and in the developing countries, at average rates of about $3 \%$ per annum; a high use of electricity generally allows people to live better and longer, as it happens in the most advanced countries. As already observed, electricity is the typical energy carrier and it is useful to examine its cycle that points out strengths and weaknesses.

Electricity can be obtained, both on a large scale and on a small scale, from fossil fuels (especially coal and natural gas), from fissile fuels (nuclear energy) and from renewable sources (hydroelectric, wind power, photovoltaic solar, ... ); it therefore has the great advantage of being able to be produced from a wide variety of sources. Furthermore it can be put to many different uses and at very varied scales. Its environmental impact is locally very positive because, as opposed to other carriers, there is no polluting emission at the place where the electricity is used.

The development of the electricity market depends also on the development of advanced technologies of electric transmission, already now indispensable for meeting the growth in demand of the deregulated markets. Unlike transport, which is consolidated and efficient, electricity storage is a weaker point of this energy carrier. By and large, electricity, once it has reached the end-user, has to be consumed immediately. This does not mean that no storage systems exist: there are several technologies covering a broad range of applications, from those able to deal within fractions of a second with variations/ interruptions of electricity (power quality) to those that enable electricity supplies to be managed according to market demand (energy management). The accumulation/storage systems are potentially useful as they can be combined with renewable sources (such as photovoltaic and wind energy) so as to mitigate their characteristics of intermittence and to ensure the recovery of the electricity produced during periods of slack demand. In recent times, continuous improvements have been achieved for storage systems based on batteries and cost is constantly decreasing along the years. However, the only energy of renewable type that has, for the moment, fully resolved this problem commercially is hydropower, as the system of pumping water back into hydroelectric basins is widespread and is used also for generating very high power.

In conclusion, electric energy, the carrier par excellence, is used everywhere and has zero emissions in its place of use. Storage is still its weaker point but it should be noted that every small improvement in this field could lead to an increase in its use well beyond all imagination. What is sure is that, especially nowadays, electricity is the most desired energy carrier from the public and it is likely that in the long term it will progressively substitute conventional carriers produced by fossil sources, also in the field of transportation. 


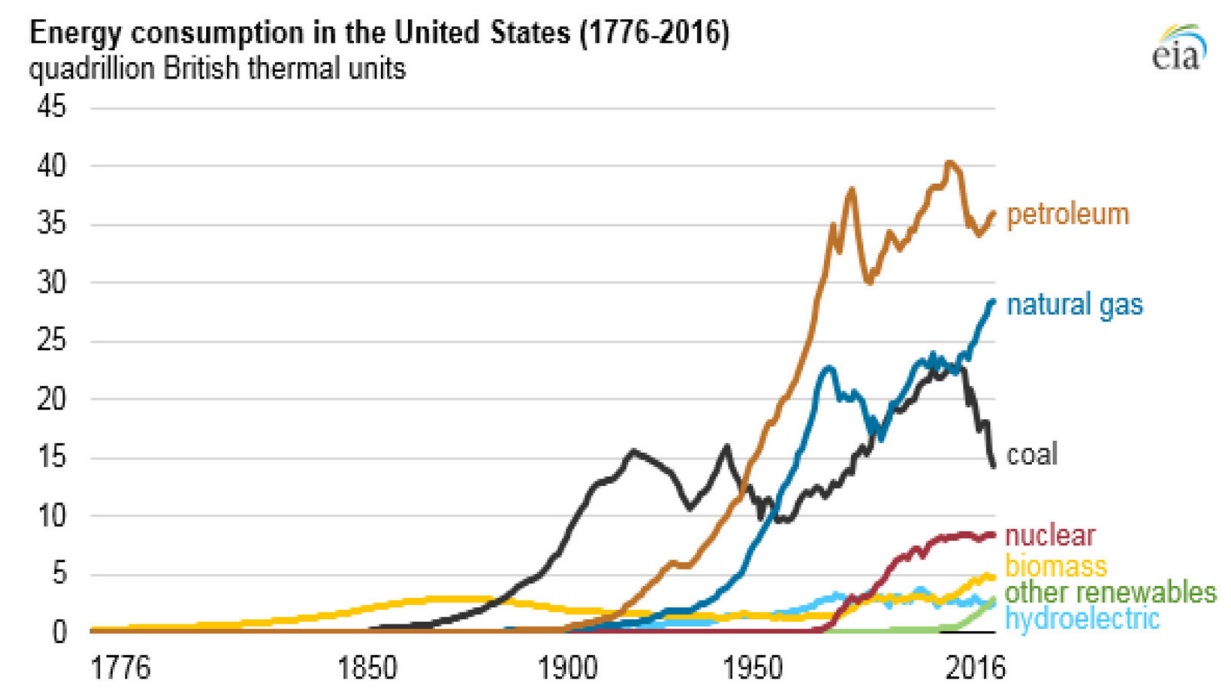

Fig. 3. - Energy consumption in the United States (1776-2016) (source EIA, 2017).

\section{2. - Fossil fuels: conventional resources}

On the other side, the present energy figures tell us another story: referring to the US (taken here as a single but very representative example) the fossil fuels have provided more than $80 \%$ of the total energy consumption for more than 100 years. According to a study of the US Energy Information Administration (EIA) [2], since 1928, when consumption of natural gas surpassed that of biomass, the three fossil fuels - petroleum, natural gas, and coal - have been the most consumed fuels in the United States. In 2016, fossil fuels accounted for $81 \%$ of the total US energy consumption (fig. 3), the lowest fossil fuel share in the past century.

In 2016, the renewable share of energy consumption in the United States was $10.5 \%$. This was the largest renewable share since the 1930s, when the overall energy consumption was lower and the amount of biomass consumption (mainly wood) was relatively high. The greatest growth in renewables over the past decade has been in solar and wind electricity generation. Liquid biofuel consumption - more than half of which is ethanol blended into motor gasoline - has also increased in recent years, contributing, especially in the US, to the growing renewable share of total energy consumption.

In addition to the increasing share of renewables, the decline in the fossil fuel share of consumption is attributable mainly to declines in coal consumption. US coal consumption fell nearly by $9 \%$ in 2016 , followed by a $14 \%$ drop in 2015 . Overall, US coal consumption has declined by almost $38 \%$ since 2005. In each of the past 20 years, the power sector has accounted for more than $90 \%$ of the total US coal consumption.

Petroleum, which encompasses nearly all transportation fuels and several petroleumbased fuels used in homes, businesses, and industries, continues to be the largest source 
of energy consumption in the United States. Petroleum consumption has increased in each of the past four years.

Consumption of natural gas has risen in nine of the past 10 years. As recently as 2006, the United States consumed more coal than natural gas (in energy-equivalent terms), but as natural gas consumption has increased - particularly in the electric power sectornatural gas use in 2016 was about twice that of coal, contributing also to a significant reduction of $\mathrm{CO}_{2}$ emissions [3].

Similar trends (with some difference) may be also extended to a worldwide figure. In Europe the renewables share is somewhat higher but there are not any radical differences, and the US situation can be extrapolated without significant differences to the world picture (maybe with the exception of a less pronounced switch of coal to natural gas, that is typical of the US situation).

Although in perspective renewables are expected to be the fastest growing energy sources [4], it is likely that fossil fuels will dominate energy use at least through 2050 . This is still due to the increased worldwide need for energy consumption, to their superior energy intensity and reliability, to the very huge numbers that underline world exposition to fossil fuels ( $>80 \%$ energy consumption) and also to the massive investments that have already been made. The mix, however, will change, according to a McKinsey study [5]:

- Natural gas, which has a lower carbon intensity than coal and petroleum, will continue to grow quickly, but the global demand for coal will likely peak around 2025. The relatively high rate of natural gas consumption growth is attributed to abundant resources and rising production — including supplies of tight gas, shale gas and coalbed methane.

- Growth in the use of oil, which is predominantly used for transport and petrochemistry (differently from all other sources that mostly produce electricity), will slow down as vehicles get more efficient [6] and more electric: here peak demand could come as soon as 2030. However, its potential decline will be very slow as the electric vehicles penetration will have to face the need of substituting a huge fleet of light duty vehicles equipped with conventional engines; presumably it will not have the same impact on heavy duty vehicles [7].

- By 2050 the McKinsey research estimates that coal will be down to just $16 \%$ of the global power generation (from $41 \%$ now) and fossil fuels to $38 \%$ (from $66 \%$ now). Overall, coal, oil and gas will continue to be $74 \%$ of the primary energy demand, down from $82 \%$ at present. After that, the rate of decline of the use of fossil fuels is likely to accelerate.

As regards oil and natural gas, impending reserves' depletion is more a myth than a reality, as proved oil reserves (only a part of resources in place) have continuously increased thanks to exploration activities, improved technology and market conditions. Furthermore the discovery of unconventional reserves (oil sands, shale oil \& gas, ...) has even more improved the overall figure. 


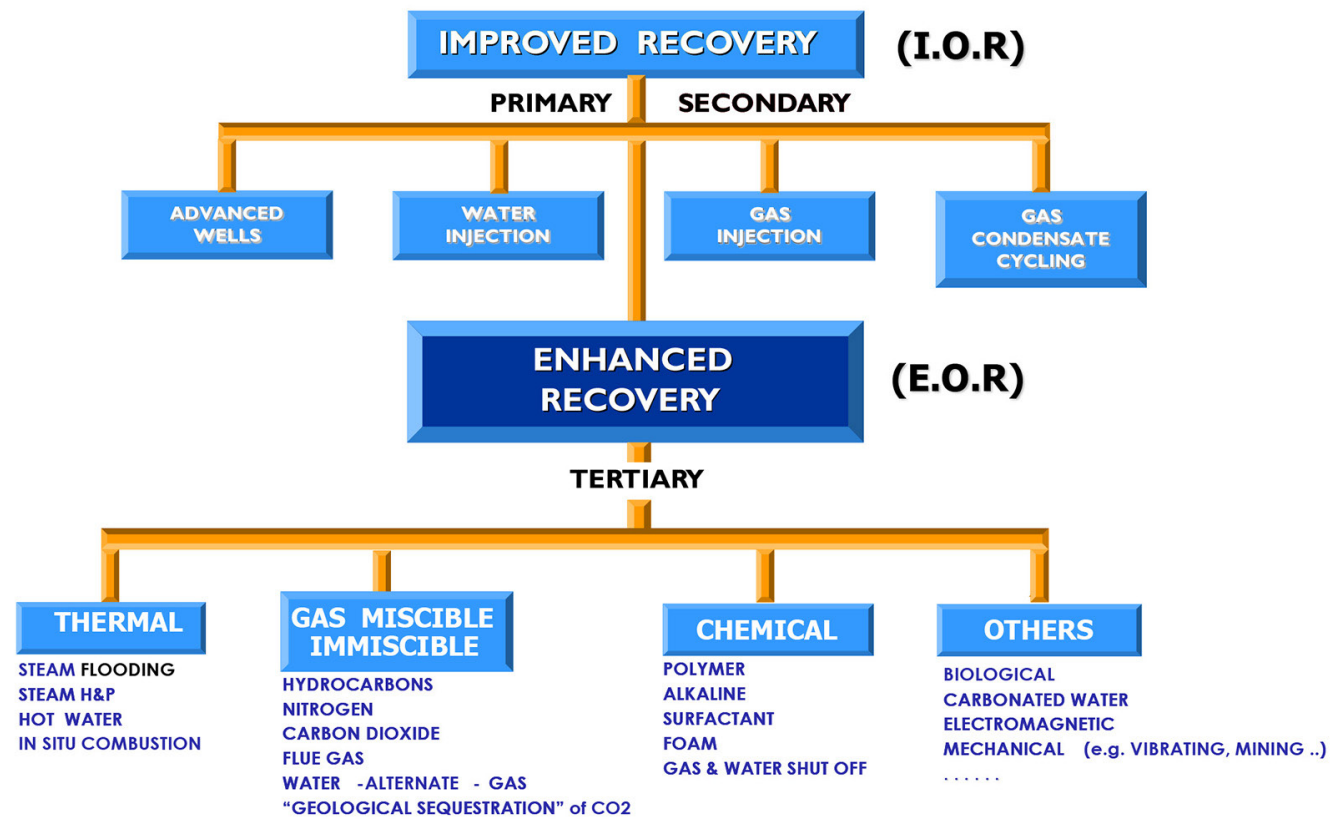

Fig. 4. - Increase of reservoir recovery factor in oil \& gas fields.

However, this does not mean that there are not challenges and dilemmas in the continuous exploitation of conventional reserves, a few of them are reported in the following:

2'1. Decline of great reservoirs for lacking of suitable technology and reservoir management. - This is a typical problem of old big reservoirs, which continue producing more water than oil: the first simplest remedy is just to pump even more water into the field to increase oil production, another opportunity may be the injection of natural gas to achieve the same effect but eventually many other techniques have been developed to increase the recovery factor of the reservoir, as shown in fig. 4.

$\mathbf{2} 2$. Increasing of water production from oil reservoirs. - Oil and natural gas companies are honing strategies for reducing production costs through effective watermanagement practices and wastewater disposal options [8]. Actually, Exploration and Production O\&G companies are among the major water producers and the major freshwater users, although they could consume less fresh water and do more to access alternate sources through recycling and reusing more produced wastewater.

The oil-price slump that started in late 2014 has forced producers to cut spending and reduce operating expenses, encouraging more innovative, efficient water management (fig. 5). It is expected that industry will intensify its focus on water management. In the next section on unconventional resources the same issue will be discussed again. 


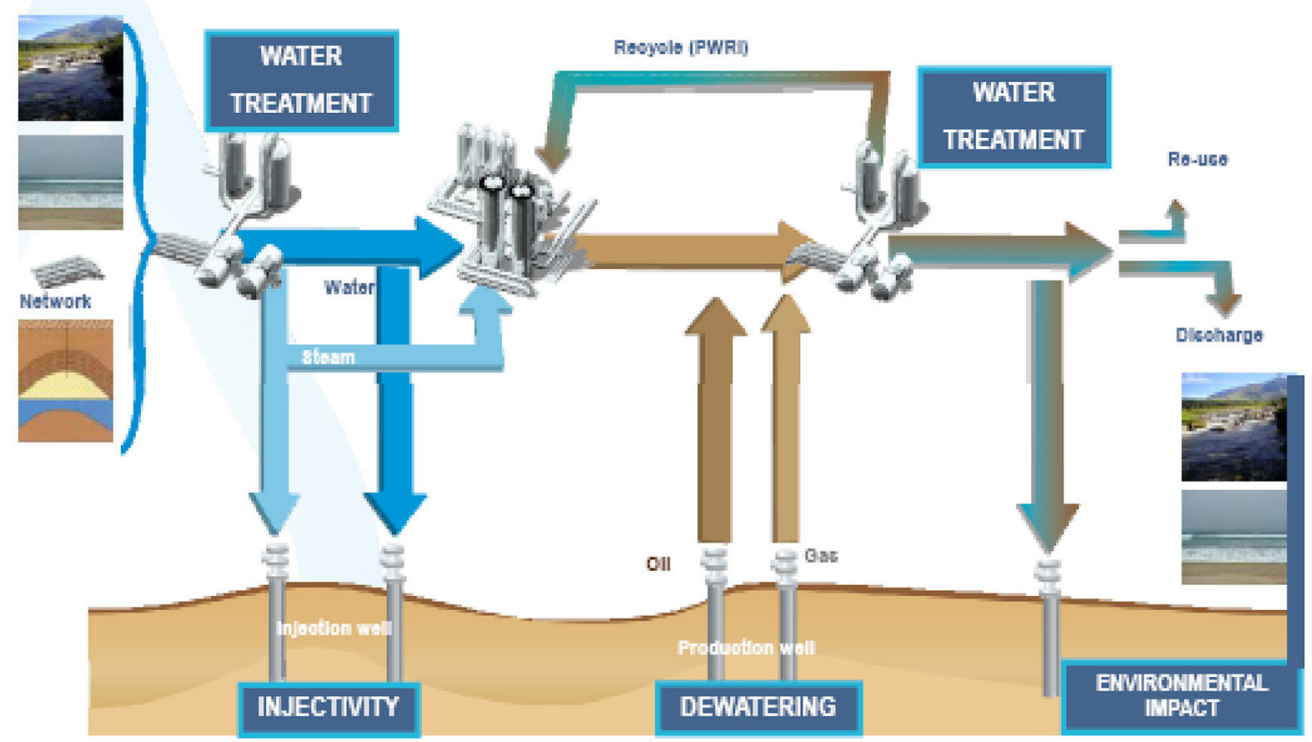

Fig. 5. - Water Management in oil \& gas fields.

2:3. Need to cope with the issue of climate change. - Fossil fuels (oil, gas and coal) are the most widely used energy sources today, accounting for more than $80 \%$ of worldwide energy consumption. Their undisputed leadership is however related to the problem of carbon dioxide $\left(\mathrm{CO}_{2}\right)$ emissions into the atmosphere, regarded as one of the main causes for climate change. Sixty per cent of the $\mathrm{CO}_{2}$ produced by mankind originates from combustion of fossil fuels (both conventional and unconventional) (fig. 6), which consequently is not the only activity that produces $\mathrm{CO}_{2}$.

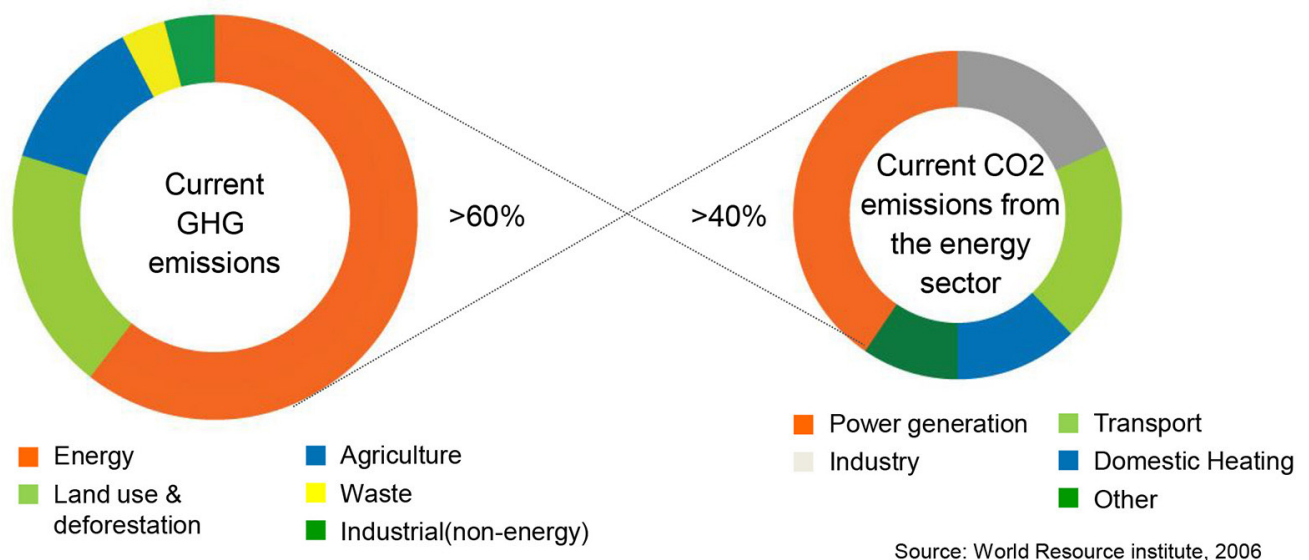

Fig. 6. - Total global man-made $\mathrm{CO}_{2}$ emissions. 
Thus the need to satisfy the growing world demand for energy, among the emerging economies in particular, goes hand in hand with the need to tackle the risks to the climate stemming from increased production of $\mathrm{CO}_{2}$.

The first solution, and the most immediately practicable approach in the short term, is energy efficiency: i.e., measures, attitudes and technologies that help reduce consumption. Another solution is to use alternative energy sources, which play a relatively modest role so far. Biomass and related materials (woody substances, various types of waste) cover about $10 \%$ of our total energy requirement, a percentage that will remain about steady. This situation seems similar in nuclear energy, which, together with hydroelectric power, covers about $8 \%$ of the total requirement. Use of other renewable energy sources (wind and solar energy) is increasing a lot, but currently satisfies only a few percent of the Earth's energy requirement.

In other words, fossil fuels will continue to dominate the world energy sector for the next two-three decades. Thus, in order to achieve a significant reduction in $\mathrm{CO}_{2}$ emissions just over the long term direct action must be taken also on the use of these sources.

A switch between coal/oil and natural gas is beneficial to reduce $\mathrm{CO}_{2}$ emissions, at least as regards power generation as demonstrated by the recent US experience.

In the long term, a further alternative can be represented by $\mathrm{CO}_{2}$ Capture and Storage (CCS) technology, used to sequester $\mathrm{CO}_{2}$ generated by fossil fuels, thereby reducing emissions into the atmosphere. The geological storage of carbon dioxide may enable real progress in the global effort to make meaningful reductions in $\mathrm{CO}_{2}$ emissions especially from large-point source emitters such as power plants, refineries, cement plants and steel mills. Of course, CCS is not a panacea, there are several issues that need to be addressed before it can achieve a widespread application, but it does offer a tangible mean to deal with large volumes of gas emissions by using technologies already at hand, or after further improvement [9].

\section{3. - Unconventional resources: the "Shale" revolution}

As mentioned above, the deployment of huge reserves of shale oil and gas have deeply modified the overall energy picture in the last ten years. By definition, shale gas is a natural gas that is found trapped within shale formations [10]. Shale gas has become an increasingly important source of natural gas especially in the United States since the start of this century, and interest has spread to potential gas shales also in the rest of the world (although with very scarce success till now, with the only exception of Argentina). In 2000 shale gas provided only 1\% of US natural gas production; by 2010 it was over $20 \%$ and the US government's Energy Information Administration predicts that by 2035, $46 \%$ of the United States' natural gas supply will come from shale gas.

Because shales ordinarily have insufficient permeability to allow significant fluid flow to a wellbore, most shales are not commercial sources of natural gas. Shale gas is one of a number of unconventional sources of natural gas; others include coalbed methane, tight sandstones, and methane hydrates. Shale gas areas are often known as resource plays (as opposed to exploration plays). The geological risk of not finding gas is low in resource plays, but the potential profits per successful well are usually also lower. 


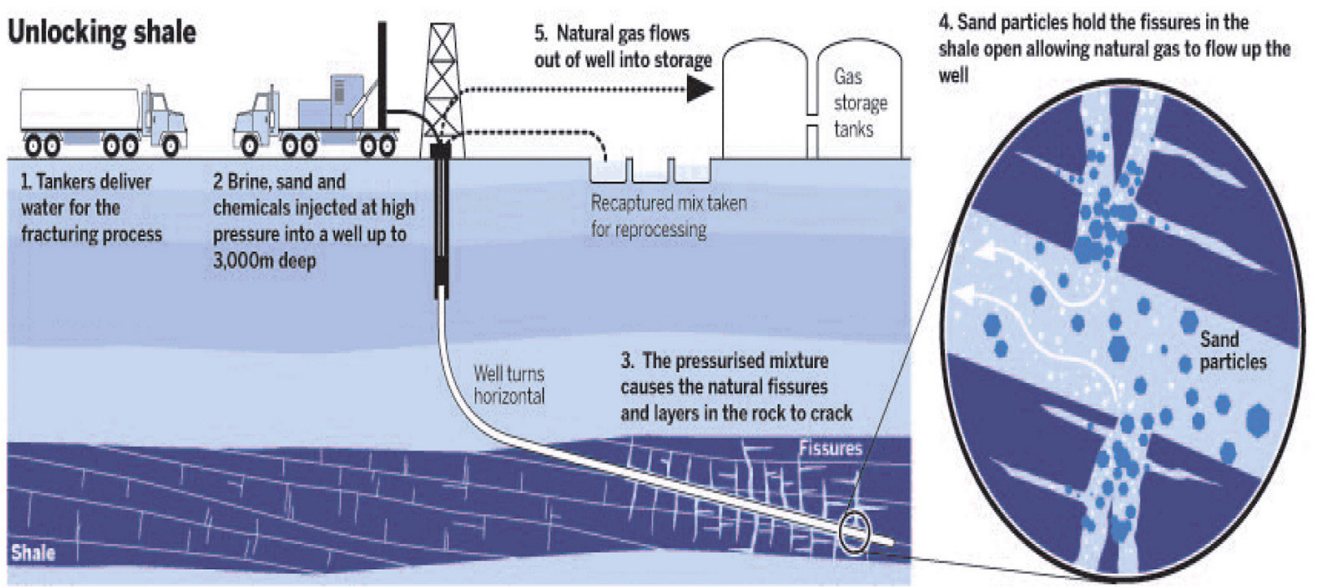

Fig. 7. - Shale gas production technology (Source: Financial Times, March 2010).

Shale has low matrix permeability, and so gas production in commercial quantities requires fractures to provide permeability. Shale gas has been produced for years from shales with natural fractures; the shale gas boom in recent years has been due to modern technology in hydraulic fracturing (fracking) to create extensive artificial fractures around wellbores.

Horizontal drilling is often used with shale gas wells (fig. 7), with lateral lengths up to 10000 feet $(3000 \mathrm{~m})$ within the shale, to create the maximum borehole surface area in contact with the shale.

Analogously, shale oil is an unconventional oil produced from oil shale rock fragments by pyrolysis, hydrogenation, or thermal dissolution. The term "shale oil" is also used for crude oil produced from shales of other very-low-permeability formations. However, in order to reduce the risk of confusion of shale oil produced from oil shale with crude oil in oil-bearing shales, the term "tight oil" is preferred for the latter.

Shale oil is extracted by pyrolysis, hydrogenation, or thermal dissolution of oil shale [11]. The pyrolysis of the rock is performed in a retort, situated either above ground or within the rock formation itself. As of 2008, most oil shale industries perform the shale oil extraction process after the rock is mined, crushed and transported to a retorting facility, although several experimental technologies perform the process in place (in situ). The temperature at which the kerogen decomposes into usable hydrocarbons varies with the time-scale of the process; in the aboveground retorting process decomposition begins at $300{ }^{\circ} \mathrm{C}$, but proceeds more rapidly and completely at higher temperatures.

Decomposition takes place most quickly at a temperature between 480 and $520^{\circ} \mathrm{C}$. Hydrogenation and thermal dissolution (reactive fluid processes) extract the oil using hydrogen donors, solvents, or a combination of these. Thermal dissolution involves the application of solvents at elevated temperatures and pressures, increasing oil output by 
cracking the dissolved organic matter. Different methods produce shale oil with different properties.

Also for shale resources the same challenges and dilemmas, previously reported for conventional O\&G sources, can be found: North American shale reservoirs contain billion of barrels of oil but the industry's average recovery factor is typically well below $10 \%$ compared with an average $30 \%$ for conventional reservoirs. Efforts to improve recovery from unconventional reservoirs are well under way [12].

On the other hand, as regards water management the situation is even more critical than in the case of conventional resources. Operators have always factored water handling into the cost of drilling and production operations. But the proliferation of hydraulic fracturing in North American shale plays has moved water handling from line item expense to central concern [13], making water treatment and re-use mandatory in perspective.

\section{4. - Concluding remarks}

By moving towards 2040-2050, oil and natural gas will remain crucial energy components, maybe with some less crude-oil production but more natural gas and higher use of electricity [14], produced both by natural gas and by renewables and also pushed by the advent of electric vehicles and by new perspective environmental regulations that could prohibit the use of diesel and gasoline vehicles at least in the cities [15].

However, the process will likely be very slow as the overall picture is very resilient due to the contemporary need of increasing energy consumption and to the difficulty to completely renew the worldwide vehicles fleet in less than decades.

\section{REFERENCES}

[1] Marchionna M., in Encyclopedia of Hydrocarbons - Treccani 3rd edition, 4.1 (Istituto dell'Enciclopedia Italiano) 2007, pp. 301-317.

[2] Hydrocarbon Processing online, July 3, 2017.

[3] Hydrocarbon Processing online, April 10, 2017.

[4] OGJ Authors, Oil \& Gas J., 115.10 (2017) 38.

[5] Nyquist S., in McKinsey \& Company Report, November 2016.

[6] Hydrocarbon Processing online, May 23, 2017.

[7] Hydrocarbon Processing online, July 3, 2017.

[8] DitTrick P., Oil $\mathscr{E}$ Gas J., 115.8 (2017) 50.

[9] Marchionna M., La Chimica \&s l'Industria (Milan), 94.6 (2012) 100.

[10] Moniz E. J., Jacoby H. D. and Meggs A. J. M., The Future of Natural Gas - an interdisciplinary MIT study (MIT Press) 2011, pp. i-178.

[11] Speight J. M., Shale Oil Production Processes (Gulf Professional Publishing - GPP) 2013, pp. 1-192.

[12] Von Flatern R., Upstream online, June 9 (2017).

[13] Von Flatern R., Upstream online, August 9 (2017).

[14] Snow N., Oil \&J Gas J. online, October 18 (2017).

[15] Hydrocarbon Processing online, July 6, 2017. 